\title{
Delaying the Timing of Offshoring Low-Skilled Tasks*
}

\author{
Felipa de Mello-Sampayo ${ }^{\S}$, Sofia de Sousa-Vale ${ }^{\dagger}$, and Francisco Camões ${ }^{\ddagger}$ \\ ${ }^{\S \dagger}$ ISCTE-Higher Institute for Labour and Business Studies, Economics Department
}

\begin{abstract}
This paper examines the impact of uncertainty on offshoring low-skilled tasks. The model shows that greater demand uncertainty adversely affects the expected profit and timing of offshoring. It is also shown that a home country tax rate deduction increases the volatility of the expected profits, making offshoring appear to be more risky. One policy implication of our results is that, in order to delay relocation of MNE's production from the home country, a government should adopt tax rate deduction rather than a direct subsidy because the former is more economical and effective than the latter.
\end{abstract}

JEL Classification: F23; D81; G38

Keywords: offshoring, Multinational Enterprises, Option-Pricing Model, Fiscal Policy

Postal address: ISCTE, Department of Economics, Av. Forças Armadas, 1649-026, Lisbon, Portugal.

${ }^{*}$ We are grateful to Ana Balcão Reis and to seminar participants at the $63 r d$ International Atlantic Economic Conference for useful comments and suggestions. We acknowledge with thanks the financial support of the Science and Technology Foundation. Corresponding author's email: filipa.sampayo@iscte.pt 


\section{Introduction}

As globalisation reaches the remotest economies in the world, a considerable number of firms engage in Foreign Direct Investment (FDI) for an increasing number of reasons, in a widening array of locations, in order to take advantage of the spawning business opportunities and also to better accommodate the blistering pace of technological change. MNEs have undergone considerable organizational changes and important contributions have been made to model different forms and degrees of involvement of business firms in foreign activities (Carr, Markusen and Markus, 2001, Ekholm, Forslid and Markusen, 2006, Helpman, 2006, Markusen, 2002).

To capture the recent trends, Grossman and Rossi-Hansberg $(2006 a, b)$ extend the traditional trade theory framework to allow for trade in tasks. Increasingly, international trade involves not only complete goods, but also individual tasks. In the new global production processes, specialization can be achieved without geographic concentration. This has allowed firms to take advantage of differences in factor costs and expertise across countries. As globalisation has advanced, it has become easier to move intermediate-level tasks offshore.

Tasks can be performed offshore either within or beyond the boundaries of the firm. Much of the recent literature on offshoring distinguishes between firms that are vertically integrated and those that contract out certain activities ${ }^{1}$. Since we assume that a firm needs the same amount of a foreign factor whether it performs a given activity in a foreign subsidiary or it outsources the activity to a foreign supplier, the organizational configuration of MNE's activities is not under scrutiny. Rather, the purpose of this paper is to investigate the role of uncertainty on offshoring low-skilled tasks. Focusing on uncertainty is relevant because emerging markets are characterized by much greater uncertainty than developed countries. They are also the potential recipients of most offshoring low-skilled tasks since their relative factor endowments and other features differ from those of mature economies where parent firms are based.

We consider the problem of a firm whose production is located exclusively in one country but is contemplating relocating its intermediate production abroad, i.e. offshoring low-skilled tasks. The firm will engage in offshoring only if such a move is deemed beneficial in the medium and long term. That in turn will depend on the perceived evolution of demand. The higher the uncertainty regarding the profitability of the offshoring initiative, the more likely it is that a favourable situation will turn into an unfavourable one, and the more the firm will gain from waiting for more information before committing itself to investment (or dis-investment) whenever there are significant sunk costs (Pindyck, 1988). This result is a prediction of the "option-pricing" approach to the analysis of irreversible investment under uncertainty (Dixit, 1989a,b, Dixit and Pindyck, 1994).

Furthermore, Grossman and Rossi-Hansberg $(2006 a, b)$ decomposed the effect of "offshoring" low-skilled jobs into three component parts: a productivity effect, a relative-price effect, and a labour supply-effect. Offshoring makes firms more productive: the tasks that are best kept close to home remain onshore and other tasks can be taken care of in cheaper places abroad. However, when some tasks are taken overseas, that leaves less work for home country employees and wages fall or, in the presence of labour-market frictions, unemployment increases. Offshoring enables companies to produce more what may depress the price of its exports on world markets, damaging the country's terms of trade, and affecting workers. Grossman and Rossi-Hansberg (2006a) describe this as a "new paradigm".

There is increasing recognition that globalisation opens up new channels through which

\footnotetext{
1 "Offshoring" means the performance of tasks in a country different from where a firm's headquarters are located whereas "outsourcing" means the performance of tasks under some contractual arrangement by an unrelated party. Thus, offshoring can be conducted in-house or at arms-length, while outsourcing can be performed in a domestic or foreign location.
} 
countries can enhance their competitiveness, including via outward FDI (see UNCTAD, 2005, 2006). From a home-country perspective, more and more countries are dismantling barriers to outward FDI. However, the effects of outward FDI on home-country employment have been a matter of concern for developed countries, especially in the context of relocation of activities by efficiency (or cost reduction) seeking Multinational Enterprises (MNEs). Similarly, the effects of outward FDI can be a concern for developing countries. Most countries have at some stage exercised control over FDI outflows through various rules and regulations to mitigate potentially negative effects from such investments. Virtually all investor countries, including the United States, have exercised some control over outward FDI from time to time. One common policy has been to limit capital outflows out of concern for the country's balance of payments. In addition, countries have occasionally manipulated tax rules to try to encourage their firms to invest at home. The objective behind such policies is to create jobs at home rather than abroad $^{2}$. Finally, countries sometimes prohibit national firms from investing in certain countries for political reasons. Such restrictions can be formal or informal.

Traditionally, when a firm engages in offshoring low-skilled tasks, home country workers that loose their jobs tend to be older, less educated and hence less easily re-employable than others. Being conscious that helping to retrain these workers improves the economy's efficiency, increases the political appeal of labour-market policies.

Hence, we also focus on how home country policies, intended to delay ${ }^{3}$ the timing of offshoring (in order to set up, for example, a retraining scheme for the workers that will be unemployed when the firms exercise the option to invest abroad), actually affect offshoring in practice. Generally, a home country either offers a tax rate deduction or provides a non-tax subsidy ${ }^{4}$. Comparing these two policies, we want to find out which one is more economical and efficient in terms of delaying the timing of MNE's offshoring tasks.

To the best of our knowledge, there is no literature studying home country policies to delay the timing of outward FDI. Most of the existing related literature focuses mainly on how the policy uncertainty or strategic consideration alters the level of investment. Others focus on the timing of FDI related to the attractiveness of host countries (Brito and de Mello-Sampayo, 2005) and, similarly, there is also literature analyzing how to use policies to attract FDI ( $\mathrm{Yu}$, Chang and Fan, 2006, Pennings, 2000).

The rest of the paper is organized as follows. Section 2 lays out the stochastic optionpricing model, specifying the two feasible modes of production (onshore and offshore) as well as examining the impact of demand shocks on both the timing of offshoring and the profits of each mode of production. Section 3 evaluates the impact of home country fiscal policies on the timing of offshoring. Section 4 concludes.

\section{The Model}

In this section, we consider an economic set-up which basically follows Aizenman and Marion (2004), Aizenman and Noy (2006). However, we go further by assuming the demand to evolve according to a geometric Brownian motion and then, in Section 3, we evaluate the effects of fiscal policies on the timing of offshoring and comparing their effects. We consider a global economy composed of two countries, Home $(h)$ and Foreign $(f)$. Asterisks indicate foreign (country $f$ )

\footnotetext{
${ }^{2}$ The British advanced corporation tax system taxed British companies' foreign earnings at a higher rate than their domestic earnings. This tax code created an incentive for British companies to invest at home.

${ }^{3}$ Bearing in mind that there is increasing recognition that countries can enhance their competitiveness via outward FDI, we assume that governments implement these policies with the intent to delay not deter FDI.

${ }^{4}$ For a non-tax subsidy we will assume a direct subsidy or a direct cash transfer to the MNE.
} 
variables.

The utility of $h$ consumers at time $\mathrm{t}$ is a semi-additive function of two goods, $Z$ and $Y$,

$$
U_{t}=Q_{Z t}+\frac{A^{1-\delta}}{\delta} Q_{Y t}^{\delta}, \quad 0<\delta<1
$$

Identical preferences characterize consumers in country $f$.

The supply of labour in each country is inelastic and given by

$$
L_{s}=\bar{L} ; L_{s}^{*}=\bar{L}^{*}
$$

The homogenous good, Z, is produced in both countries using a simple Ricardian technology. This technology is

$$
Q_{Z t}^{S}=a \cdot L_{t}, \quad Q_{Z t}^{S *}=a^{*} \cdot L_{t}^{*}
$$

where the parameters $a$ and $a^{*}$ are the productivity of home and foreign labour, respectively, the real wage is $w=a$ and $w^{*}=a^{*}$. Good $\mathrm{Z}$ is characterized by stable and mature technology, with limited prospects for future productivity improvements.

Good $\mathrm{Y}$ is produced by a monopoly using a fragmented production mode where production of intermediate Y inputs can be done onshore or offshore. Good Y is a relatively high tech good, the outcome of multinationals' R\&D. Our modelling strategy is designed to highlight, in the simplest way, how the relocation of production affects profitability under uncertainty. Hence, we abstract from various considerations. We assume that a firm needs the same amount of a foreign factor whether it performs a given activity in a foreign subsidiary or whether it outsources the activity to a foreign supplier. The organizational configuration of MNE's activities is not under scrutiny. Furthermore, heterogeneous tastes and transportation costs do not enter directly into the model.

The MNE is located at home producing the intermediate and final production stages of good Y. The intermediate input, $M$, is produced at time $\mathrm{t}$ using a Cobb-Douglas production technology:

$$
Q_{M t}^{S}=b \sqrt{L_{M t}},
$$

where $L_{M t}$ is the labour employed, $b$ is labour productivity in the home intermediate-good sector. The final production stage combines intermediate input $M$ and domestic labour using a Leontief technology to produce Y, where

$$
f\left(Q_{Y t}\right)=\operatorname{Min}\left[Q_{M t}^{S} ; b \sqrt{L_{t}}\right]
$$

However, if the firm expands its intermediate production to a foreign country, the final production stage is done at $h$, using intermediate inputs produced in $f$ at an earlier stage in the developing country that offers the most cost effective production line $\left(W^{*}<W\right)$. Whether the MNE performs a given activity in a foreign subsidiary or outsources the activity to a foreign supplier, results in a total set-up $\operatorname{cost}^{5}$ of I. The intermediate input, $M_{i}$, can be produced in the foreign country at time t using a Cobb-Douglas production technology:

$$
Q_{M t}^{S *}=b^{*} \sqrt{L_{M t}^{*}}
$$

$L_{M t}^{*}$ is the labour employed, $b^{*}$ is labour productivity in the foreign intermediate-good sector.

\footnotetext{
${ }^{5}$ For example, if the MNE offshores the activity to a foreign subsidiary, the foreign production process requires the multinational to invest in one plant. However, if the firm engages in outsourcing, this may be reflected in contract and supervision costs.
} 
Applying (1), the constant elasticity of demand for good $\mathrm{Y}$ in each country is

$$
Q_{Y t}^{D}=A\left[\frac{1}{P_{t}}\right]^{\eta}, \quad \eta=\frac{1}{1-\delta}>1,
$$

where $Q_{Y t}^{D}$ is the total quantity demanded of the product market at time t, $P_{t}$ is the market price at time $\mathrm{t}, \eta$ is the parameter for the elasticity of demand ${ }^{6}$, and $A$ is the level of the state variable that represents the random shock of the demand side at time t. For analytical tractability, the state variable is assumed to evolve according to a geometric Brownian motion:

$$
d A=\alpha A d t+\sigma A d z
$$

where $d z=\varepsilon_{t} \sqrt{d t}$ is the increment of a Wiener process and

$$
\varepsilon_{t} \curvearrowright N(0,1), \quad E\left(\varepsilon_{t}, \varepsilon_{s}\right)=0 \text { for } s \neq t
$$

Equation (8) implies that the current value of the random shock is known, but the future values are log-normally distributed with a variance growing linearly with the time horizon.

We calculate employment and profit for the multinational engaged in producing solely at home. Let the tax rate on profit in country $h$ be $r$, and the operating profits $\pi$, so it earns $(1-r) \pi$. Applying Equations (4) and (5), it follows that employment in the final-good sector $(\mathrm{Y})$ and in the intermediate-good sector $(\mathrm{M})$ is:

$$
L_{Y t}=\frac{\left(Q_{Y t}^{S}\right)^{2}}{b^{2}}, \quad L_{M t}=\frac{\left(Q_{M t}^{S}\right)^{2}}{b^{2}}
$$

By maximizing the profit flow at time $t, \pi_{h}$ can be derived as

$$
\pi_{h}=A^{\theta}\left(1-\frac{\delta}{2}\right) \delta^{\phi}(1-r)\left(\frac{2 w}{b^{2}}\right)^{-\phi},
$$

where $\theta=\frac{2(\delta-1)}{\delta-2}=\frac{2}{\eta+1}$ and $\phi=\frac{\delta}{2-\delta}$. Using Ito's lemma, it can be confirmed that $A^{\theta}$ also follows a geometric Brownian motion: $d A^{\theta}=\left(\alpha \theta-\frac{\theta \phi}{2} \sigma^{2}\right) A^{\theta} d t+\theta \sigma A^{\theta} d z$.

Now we calculate employment and profit for the multinational engaged in offshoring. Here we assume that the home country is exempting foreign-source income, i.e. foreign-source income is subject to the tax levied by the host country only, ${ }^{7}$ so that the host country tax rate becomes irrelevant for investment decisions in the home country. Applying Equations (5) and (6), it follows that:

$$
L_{Y t}=\frac{Q_{t}^{2}}{b^{2}}, \quad L_{M t}^{*}=\frac{Q_{t}^{2}}{b^{* 2}}
$$

By maximizing the profit flow at time $t, \pi_{o}$ can be derived as

$$
\pi_{o}=A^{\theta}\left(1-\frac{\delta}{2}\right) \delta^{\phi}(1-r)\left(\frac{w}{b^{2}}+\frac{w^{*}}{b^{* 2}}\right)^{-\phi}
$$

Proposition 1: Higher volatility of demand shocks reduces the expected profit associated with both onshoring and offshoring low-skilled tasks.

\section{Proof:}

Comparing the state variables in Equations (24) and (25) in Appendix A, it follows that expected

\footnotetext{
${ }^{6}$ Since the demand is downward-sloping and the profit flow is non-negative, we require that $0<\delta<1$, so $\eta>1$.

${ }^{7}$ We could also assume that the home country is granting tax credits, i.e. the home country taxes its residents on their world-wide income and grants full credit for foreign taxes, and thus, in principle, the foreign-source income is taxed at the source-country tax rate.
} 
profits are proportional to $A^{\theta}$ under both production modes. Recalling that a monopoly operates where demand is elastic $(\eta>1)$, it follows that $\theta=2 /(1+\eta)<1$. Hence, expected profits are concave with respect to the global demand shock. Consequently, demand uncertainty reduces expected profits under both production modes ${ }^{8}$.

When the firm is producing exclusively in the home country its decision as to whether or not to engage in offshoring constitutes an optimal stopping problem for which the relevant Bellman equation is:

$$
V^{h}(A, t)=\operatorname{Max}\left\{V^{o}-I ; \Pi_{h}+\frac{1}{t} E\left[d V^{h}\right]\right\},
$$

where $V^{h}(A, t)$ is the value of the option to invest in a foreign country, $V^{o}-I$ accounts for the expected MNE's value gain that results from opting for offshoring, and the second term in curly brackets yields the time-discounted expected increment in the value of the option that arises from keeping the option unexercised for an additional lapse of time, $d t$. The range of values for which the second term in curly brackets is greater than the first defines the continuation region, where it is optimal not to exercise the option.

Proposition 2: The firm will only invest abroad if the $M N E^{\prime} s$ value associated with offshoring exceeds that of a situation of exclusive home production, i.e.

$$
A \leq \tilde{A}=\left[\frac{\beta_{1}}{\beta_{1}-1} \times \frac{\mu-\alpha \theta+\frac{\theta \phi}{2} \sigma^{2}}{1-\frac{\delta}{2}} \times \frac{\theta \delta^{-\phi}}{(1-r)\left[\left(\frac{w}{b^{2}}+\frac{w^{*}}{b^{* 2}}\right)^{-\phi}-\left(\frac{2 w}{b^{2}}\right)^{-\phi}\right]} \times I\right]^{\frac{1}{\theta}}
$$

Proof: See Appendix A.

It follows from Equation (14) and the previous assumptions on the parameters that the value of $\tilde{A}$ is greater than zero, implying that the firm will only invest abroad if the MNE's value associated with offshoring exceeds that of a situation of exclusive home production, and that is due to uncertainty of the future path of demand.

Moreover, since

$$
\frac{\partial \tilde{A}}{\partial \sigma^{2}}>0 \text { and } \lim _{\sigma \rightarrow \infty} \tilde{A}=\infty,
$$

the greater the volatility of the demand (i.e. the higher $\sigma^{2}$ ) the higher the critical value has to be to make it optimal for the firm to invest abroad. The more profitable the expected trend of demand, the less the offshoring option is worth, and thus the lower the value that triggers offshoring-entry, i.e.

$$
\frac{\partial \tilde{A}}{\partial \alpha}<0
$$

The reason for this is that the more profitable the expected trend of demand, the lower the uncertainty that results from the switch from a situation where production is exclusively carried out at home to one where the firm extends its production facilities abroad.

In regard to the discount rate, the greater the firm's time discount rate, the less it values the offshoring option and thus the lower the value A that triggers optimal entry; i.e.

$$
\frac{\partial \tilde{A}}{\partial \mu}<0
$$

This result stems from the fact that a higher time preference increases the firm's opportunity cost of not immediately investing abroad. In the extreme case where the firm cares only about

\footnotetext{
${ }^{8}$ Under our set up model, the magnitude of this adverse effect is identical for both production modes (onshore and offshore). For general values of the labour supply elasticities, as long as labour is subject to diminishing marginal productivity, demand uncertainty adversely affects both production modes, but the magnitudes of these adverse effects depend on the precise values of the labour supply elasticities.
} 
the present moment, so that $\mu \rightarrow \infty$, then $\lim _{\mu \rightarrow \infty} \frac{\beta_{1}}{\beta_{1}-1}=0$ and $\tilde{A}=0$, so that uncertainty is disregarded and the value of the offshoring option collapses to zero.

Lastly,

$$
\frac{\partial \tilde{A}}{\partial w}<0 \text { and } \frac{\partial \tilde{A}}{\partial w^{*}}>0,
$$

the lower the wage in the foreign labour market and the higher the wage in the home labour market, the lower the threshold for offshoring.

These results are extended for Equation (14) using simulations. The simulations are performed against a benchmark case (see Appendix B for description of the benchmark case). Figures 1-4 provide a sensitivity analysis of the trigger value $\tilde{A}$ with respect to the following parameters of the model: $\sigma, \alpha, \mu, w / b^{2}$ and $w^{*} / b^{* 2}$. The simulations carried out on the critical values of demand shock confirm the results of the comparative statics discussed above. Figure (1) reveals that the trigger value is much more sensitive to $\sigma$ than to $\alpha$. This is due to the fact that the higher the uncertainty, the higher the risk of foreign investments' returns and thus the higher the threshold be in order to trigger offshoring-entry. The accentuated curvature of the surface graphed in Figure (1), in which the critical value of demand shock rises very fast as both $\sigma$ is high and $\alpha$ is negative, indicates that the more the expected trend of demand is less profitable, the more the uncertainty of the offshoring decision becomes dominant. Figure (2) illustrates that the dampening influence of higher $\mu$ on the critical value strengthens as $\sigma$ increases.

\section{(Insert Figure 1 here)}

\section{(Insert Figure 2 here)}

Figure (3) shows that the trigger value rises when both $\sigma$ and $w^{*} / b^{* 2}$ increase. It illustrates that as the foreign country becomes less labour competitive, the uncertainty about the offshoring decision becomes more dominant. With limited substitutability, low productivity in a foreign location will increase the demand for labour in order to compensate for the decrease in productivity. If we were analysing a horizontal MNE, it would have experienced a fall in the demand for labour as output shifted to more productive locations. On the other hand, Figure (4) illustrates that as the home country becomes more labour competitive, the uncertainty about the offshoring decision becomes more dominant.

(Insert Figure 3 here)

(Insert Figure 4 here)

\section{Delaying Offshoring: Subsidy versus Tax Rate Deduction}

We now consider the case where country $h$, in order to delay relocation of production, subsidizes the MNE by implementing the tax deduction, $i$, on the profit earned in its own country before offshoring takes place, and so the MNE earns $(1-r+i) \pi_{h}$. The critical value is now ${ }^{9}$ :

$$
\tilde{A}_{i}=\left[\frac{\beta_{1}}{\beta_{1}-1} \times \frac{\mu-\alpha \theta+\frac{\theta \phi}{2} \sigma^{2}}{1-\frac{\delta}{2}} \times \frac{\theta \delta^{-\phi}}{(1-r)\left(\frac{w}{b^{2}}+\frac{w^{*}}{b^{* 2}}\right)^{-\phi}-(1-r+i)\left(\frac{2 w}{b^{2}}\right)^{-\phi}} \times I\right]^{\frac{1}{\theta}}
$$

Note that $\frac{\partial A_{i}}{\partial i}>0$. This means that a more favourable tax rate deduction will delay the timing of offshoring. Figure (5) illustrates the impact of $\sigma$ and $i$ on the critical value of offshoring ${ }^{10}$.

\footnotetext{
${ }^{9}$ Equation (15) is derived in the same way as Equation (14).

${ }^{10}$ The parameters are calibrated with the values shown in Appendix B.
} 
If $A_{i} \leq \tilde{A}$ the MNE invests and gets the value $V^{o}-I$. If $A_{i}>\tilde{A}$, the MNE will wait until the threshold is hit, and at that point, the MNE gets $V^{o}-I$ and receives additional profit flow until $\mathrm{T}$, its expected present value (EPV), denoted by $V^{i}$, is:

$$
V^{i}=E\left\{\int_{0}^{T} e^{-r t} A^{\theta}\left(1-\frac{\delta}{2}\right) \delta^{\phi}(1-r+i)\left(\frac{2 w}{b^{2}}\right)^{-\phi} d t\right\}+E\left\{e^{-r T}\right\}\left[V^{o}-I\right]
$$

Computing the expectations ${ }^{11}$, we get:

$V^{i}=\left[1-\left(\frac{A}{A_{i}}\right)^{\beta_{1}-\theta}\right] A^{\theta} \frac{\left(1-\frac{\delta}{2}\right) \delta^{\phi}(1-r+i)}{\mu-\alpha \theta+\frac{\theta \phi}{2} \sigma^{2}}\left(\frac{2 w}{b^{2}}\right)^{-\phi}+\left(\frac{A}{A_{i}}\right)^{\beta_{1}}\left[A_{i}^{\theta} \frac{\left(1-\frac{\delta}{2}\right) \delta^{\phi}(1-r)}{\mu-\alpha \theta+\frac{\theta \phi}{2} \sigma^{2}}\left(\frac{w}{b^{2}}+\frac{w^{*}}{b^{* 2}}\right)^{-\phi}-I\right]$

We also consider the case where country $h$ implements a direct subsidy to delay relocation of production. The subsidy is proportional to the entry cost ${ }^{12}$, denoted by s and assume $0<s<1$. The total irreversible entry cost is now augmented to $(1+s) I$. In the same way that Equation (14) is derived, we have the critical value:

$$
\tilde{A}_{s}=\left[\frac{\beta_{1}}{\beta_{1}-1} \times \frac{\mu-\alpha \theta+\frac{\theta \phi}{2} \sigma^{2}}{1-\frac{\delta}{2}} \times \frac{\theta \delta^{-\phi}}{(1-r)\left[\left(\frac{w}{b^{2}}+\frac{w^{*}}{b^{* 2}}\right)^{-\phi}-\left(\frac{2 w}{b^{2}}\right)^{-\phi}\right]} \times I(s+1)\right]^{\frac{1}{\theta}}
$$

Note that $\frac{\partial A_{s}}{\partial s}>0$. This means that a more favourable subsidy will delay the timing of offshoring. Figure (6) illustrates the impact of $\sigma$ and $s$ on the critical value of offshoring.

(Insert Figure 6 here)

If $A_{s} \leq \tilde{A}$ the MNE invests and gets the value $V^{o}-I$. If $A_{s}>\tilde{A}$, the MNE will wait until the threshold is hit, and at that point, the MNE gets $V^{o}-I$ and meanwhile receives the subsidy and additional profit flow until $\mathrm{T}$, its expected present value (EPV), denoted by $V^{s}$, is:

$$
V^{s}=s I+E\left\{\int_{0}^{T} e^{-r t} A^{\theta}\left(1-\frac{\delta}{2}\right) \delta^{\phi}(1-r)\left(\frac{2 w}{b^{2}}\right)^{-\phi} d t\right\}+E\left\{e^{-r T}\right\}\left[V^{o}-I\right]
$$

Computing the expectations, we get:

$$
V^{s}=s I+\left[1-\left(\frac{A}{A_{s}}\right)^{\beta_{1}-\theta}\right] A^{\theta} \frac{\left(1-\frac{\delta}{2}\right) \delta^{\phi}(1-r)}{\mu-\alpha \theta+\frac{\theta \phi}{2} \sigma^{2}}\left(\frac{2 w}{b^{2}}\right)^{-\phi}+\left(\frac{A}{A_{s}}\right)^{\beta_{1}}\left[A_{s}^{\theta} \frac{\left(1-\frac{\delta}{2}\right) \delta^{\phi}(1-r)}{\mu-\alpha \theta+\frac{\theta \phi}{2} \sigma^{2}}\left(\frac{w}{b^{2}}+\frac{w^{*}}{b^{* 2}}\right)^{-\phi}-I\right]
$$

Equating Equations (15) and (18), we obtain the value of s, assuming that the timing of investment is the same under both fiscal policies:

$$
s=\frac{i\left(\frac{2 w}{b^{2}}\right)}{(1-r)\left(\frac{w}{b^{2}}+\frac{w^{*}}{b^{* 2}}\right)^{-\phi}-(1-r+i)\left(\frac{2 w}{b^{2}}\right)^{-\phi}}
$$

Proposition 3: While holding their critical value equal, the expected present value of the tax rate deduction is smaller than that of the entry cost subsidy.

\section{Proof:}

We compare the expected present value of the subsidy and the tax rate deduction while holding

\footnotetext{
${ }^{11}$ This solution strategy borrows from Dixit and Pindyck (1994), p. 316.

${ }^{12}$ In order to simplify the mathematics, we assume direct subsidy to be proportional to the entry cost.
} 
their critical values equal. The difference between the expected present value of the subsidy and the tax rate deduction $\left(\triangle=V^{s}-V^{i}\right)$, using Equations (15), (18) and (21) is:

$\triangle=\left\{\left[\frac{(1-r)\left(\frac{w}{b^{2}}+\frac{w^{*}}{b^{*} 2}\right)^{-\phi}-(1-r+i)\left(\frac{2 w}{b^{2}}\right)^{-\phi}}{(1-r)\left[\left(\frac{w}{b^{2}}+\frac{w^{*}}{b^{* 2}}\right)^{-\phi}-\left(\frac{2 w}{b^{2}}\right)^{-\phi}\right]}\right]^{\beta_{1}-\theta}-1\right\} A^{\theta} \frac{\left(1-\frac{\delta}{2}\right) \delta^{\phi}}{\mu-\alpha \theta+\frac{\theta \phi}{2} \sigma^{2}}(i)\left(\frac{2 w}{b^{2}}\right)^{-\phi}+\frac{(i)\left(\frac{2 w}{b^{2}}\right)^{-\phi} I}{(1-r)\left(\frac{w}{b^{2}}+\frac{w^{*}}{b^{* 2}}\right)^{-\phi}-(1-r+i)\left(\frac{2 w}{b^{2}}\right)^{-\phi}}$

$\triangle>0$, since $\beta_{1}-\theta>0$. This result occurs because the subsidy is received independently of the MNE's expected performance, hence it does not affect the uncertainty underlying the decision of offshoring. On the other hand, the tax rate deduction increases the volatility of the expected profits, making offshoring appear to be more risky. Thus, the tax rate reduction increases the uncertainty faced by the MNE when deciding to engage in offshoring.

This result is confirmed by comparing Figures (5) and (6). The accentuated curvature of the surface graphed in Figure (5), in which the critical value of the demand shock rises very fast as both $\sigma$ and $i$ are high, indicates that the lower the tax rates, the more the uncertainty of the offshoring decision becomes dominant.

Moreover, the difference between the expected present value of the entry cost subsidy and the tax rate deduction increases with the volatility of the random shock, but decreases with the drift rate of the random shock. This shows that the cost advantage of the tax rate deduction is magnified when the demand is more volatile or the expected trend of demand is less profitable.

Proposition 4. While holding the expected present value equal, the critical value under the tax rate deduction is higher than that under the subsidy.

\section{Proof:}

From Proposition 3, we know that $V^{s}-V^{i}>0$. From Equation (15), we also know that $V^{i}$ is positively related to $A_{i}{ }^{13}$. This means that, when we raise the expected present value of the tax rate deduction $\left(V^{i}\right)$, the critical value under the tax rate deduction $\left(A_{i}\right)$ will rise. If we increase $V^{i}$ and hold $V^{s}$ unchanged such that $V^{s}=V^{i}$, then $A_{i}$ becomes higher, whereas $A_{s}$ remains unchanged.

The intuition behind Proposition 4 is that, when the government offers the tax rate deduction, the MNE will face more profit variance than under the subsidy, i.e. the tax rate deduction has the reverse effect of "profit-smoothing" ${ }^{14}$. It is the tax rate deduction's augmented uncertainty that induces a later departure, when holding the expected present value of entry cost subsidies and tax rate deduction equal.

Thus, a home government hoping to delay offshoring by home-based MNEs should make more efforts to lower tax rates rather than to subsidize the MNE, because the tax rate deduction is relatively economical and efficient.

\section{Conclusion}

In an ever faster-changing market environment, the optimal timing for expanding abroad becomes increasingly relevant for firms considering engaging in offshoring low-skilled tasks. In this regard, this paper sets up a stochastic model that provides an optimal rule for the timing of offshoring. In the real world, demand fluctuations among others render the outcome of any investment uncertain, so that a firm might have to wait for more information before optimally engaging in offshoring, especially when investment costs cannot be fully recovered later on. Since, in most cases, the firm is not compelled to engage in offshoring at any specific moment, it holds an option to invest abroad that should only be exercised when it is optimal to do so.

\footnotetext{
${ }^{13}$ Note that $\frac{\partial V^{i}}{\partial A_{i}}>0$.

${ }^{14}$ Like "consumption-smoothing" smoothes consumption over time, "profit-smoothing" reduces volatility of profits over time.
} 
Focusing on uncertainty is important because emerging markets are potential recipients of most offshoring low-skilled tasks, since their relative factor endowments and other features differ from those of mature economies where parent firms are based, and because developing countries are also characterized by much greater uncertainty than developed countries. Viewing from the perspective of real option theory, this paper sheds new light on some debates about offshoring low-skilled tasks. Our theoretical model suggests that demand uncertainty reduces expected profits under onshoring and offshoring low-skilled tasks. In addition, demand volatility discourages offshoring low-skilled tasks. The stochastic model also illustrates that as the foreign country becomes less labour competitive, the uncertainty of the demand becomes more dominant. With limited substitutability, low productivity in a foreign location will increase the demand for labour in order to compensate for the decrease in productivity. If we were analysing a horizontal MNE, it would have experienced a fall in the demand for labour as output shifted to more productive locations. This increases the uncertainty of the offshoring venture.

Traditionally, when a firm engages in offshoring low-skilled tasks, home country workers that loose their jobs tend to be older, less educated and hence less easily re-employable than others. We assume that governments tend to delay the timing of offshoring in order to set up, for example, a retraining scheme for the workers that will be unemployed when the firms exercise the option to invest abroad. We provide some answers about how home countries' fiscal policies affect offshoring timing as well as which policy a host government should adopt to delay the timing of offshoring. We show that, while holding their thresholds equal, a tax rate deduction costs less than a direct subsidy. Also, while holding the expected present value of the tax rate deduction and direct subsidy equal, the tax rate deduction would more greatly delay the timing of offshoring than the direct subsidy would. One meaningful policy implication of our results is that a home government, hoping to delay the MNE's offshoring decision, should make more efforts to offer tax rate deductions than to offer non-tax subsidies, because the tax rate deduction is relatively economical and efficient. 


\section{References}

Aitchison, J. and Brown, J. (1957), The Lognormal Distribution, Cambridge: Cambridge University Press.

Aizenman, J. and Marion, N. (2004), 'The merits of horizontal versus vertical fdi in the presence of uncertainty', Journal of International Economics 62, 125-148.

Aizenman, J. and Noy, I. (2006), 'FDI and trade. two-way linkages?', The Quarterly Review of Economics and Finance 46, 317-337.

Brito, J. B. and de Mello-Sampayo, F. (2005), 'The timing and probability of fdi: an application to us multinational enterprises', Applied Economics .

Carr, D., Markusen, J. R. and Markus, K. E. (2001), 'Estimating the knowledge-capital model of the multinational enterprize', American Economic Review .

Dixit, A. (1989a), 'Entry and exit decisions under uncertainty', Journal of Political Economy 97, 620-638.

Dixit, A. (1989b), 'Hysteresis, import penetration, and exchange rate pass-through', Quarterly Journal of Economics 104, 205-228.

Dixit, A. and Pindyck, R. (1994), Investment under Uncertainty, Princeton: Princeton University Press.

Ekholm, K., Forslid, R. and Markusen, J. R. (2006), Export-platform foreign direct investment, Working Paper 9517, National Bureau of Economic Research.

Grossman, G. M. and Rossi-Hansberg, E. (2006a), The rise of offshoring: It's not wine for cloth anymore, The New Economic Geography: Effects and Policy Implications, Federal Reserve Bank of Kansas City.

Grossman, G. M. and Rossi-Hansberg, E. (2006b), Trading tasks: A simple theory of offshoring, Working Paper 12721, National Bureau of Economic Research.

Helpman, E. (2006), Trade, FDI, and the organization of firms, Working Paper 12091, National Bureau of Economic Research.

Markusen, J. R. (2002), Multinational Firms and the Theory of International Trade, The MIT Press, Cambridge, Massachussets.

Pennings, E. (2000), 'Taxes and stimuli of investment under uncertainty', European Economic Review 44, 383-391.

Pindyck, R. (1988), 'Irreversible investment, capacity choice, and the value of the firm', American Economic Review 78, 969-985.

UNCTAD (2005), World investment report 2005: Transnational corporations and the internationalization of R\&D, Technical report, New York and Geneva.

UNCTAD (2006), World investment report 2006: FDI from developing and transition economies: Implications for development, United Nations, New York and Geneva.

Yu, C.-F., Chang, T.-C. and Fan, C.-P. (2006), 'FDI timing: Entry cost subsidy versus tax rate reduction', Economic Modelling 24, 262-271. 


\section{Appendix}

A

Proof: (Proposition 1)

The profit flows before relocation of production are given by the intertemporal profit function when the firm is constantly optimizing over time:

$$
\Pi_{h}=E_{t} \int_{0}^{\infty}\left[\pi_{h} e^{-\mu(\tau-t)} d \tau\right]
$$

Bearing in mind that $\mathrm{A}(\mathrm{t})$ follows a geometric Brownian motion, the properties of the lognormal distribution $^{15}$ can be used to transform Equation (23) into:

$$
\Pi_{h}=\frac{\pi_{h}}{\mu-\alpha \theta+\frac{\theta \phi}{2} \sigma^{2}},
$$

provided that $\mu-\alpha \theta+\frac{\theta \phi}{2} \sigma^{2}>0$, which will be assumed here.

The same applies to the profit flows after relocation of production, i.e.:

$$
\Pi_{o}=E_{t} \int_{0}^{\infty}\left[\pi_{o} e^{-\mu(\tau-t)} d \tau\right]=\frac{\pi_{o}}{\mu-\alpha \theta+\frac{\theta \phi}{2} \sigma^{2}},
$$

provided that $\mu-\alpha \theta+\frac{\theta \phi}{2} \sigma^{2}>0$, which will be assumed here.

Proof: (Proposition 2)

In the continuation region the Bellman equation is given by:

$$
\mu V^{h}(A, t)=\Pi_{h}+\frac{1}{t} E\left[d V^{h}\right],
$$

where $\Pi_{h}$ is given by Equation (23).

Applying Ito's lemma to the RHS of Equation (26) yields the partial differential equation:

$$
\frac{\partial V^{h}}{\partial A} \alpha A+\frac{1}{2} \frac{\partial^{2} V^{h}}{\partial A^{2}} \sigma^{2} A^{2}-\mu V^{h}+\Pi_{h}=0
$$

The general solution to the above stated differential equation has the form:

$$
V^{h}=B_{1} A^{\beta_{1}}+B_{2} A^{\beta_{2}}+\Pi_{h}
$$

where $A_{1}, A_{2}$ are constants that are yet to be determined, and $\beta_{1}, \beta_{2}$ are the roots of the characteristic equation $Q(\beta)=\frac{\sigma^{2}}{2} \beta^{2}+\left(\alpha-\frac{\sigma^{2}}{2}\right) \beta-\mu=0$. The two roots are $\beta_{1}=\frac{1}{2}-\frac{\alpha}{\sigma^{2}}+$ $\sqrt{\left(\frac{\alpha}{\sigma^{2}}-\frac{1}{2}\right)^{2}+\frac{2 \mu}{\sigma^{2}}}$ and $\beta_{2}=\frac{1}{2}-\frac{\alpha}{\sigma^{2}}-\sqrt{\left(\frac{\alpha}{\sigma^{2}}-\frac{1}{2}\right)^{2}+\frac{2 \mu}{\sigma^{2}}}$. Since the coefficient of $\beta^{2}$ is positive, $Q(\beta)$ is an upward pointing parabola. Moreover, since $Q(1)=\alpha-\mu$ and $Q(0)=-\mu$ are both negative by previous assumption, it follows that $\beta_{1}>1$ and $\beta_{2}<0$.

In order to satisfy the boundary condition ${ }^{16}, V^{h}(0)=0$, we must have $A_{2}=0$ and the general solution to Equation (27) simplifies to

$$
V^{h}=B_{1} A^{\beta_{1}}+\Pi_{h},
$$

\footnotetext{
${ }^{15}$ See Aitchison and Brown (1957).

${ }^{16}$ If A reaches zero, the profit will stay at zero afterwards, in which case the value of the MNE will have no value.
} 
where $\Pi_{h}$ is now given by Equation (24)

The set of boundary conditions that applies to this optimal stopping problem is composed of a value-matching condition,

$$
V^{h}(\tilde{A})=V^{o}(\tilde{A})-I,
$$

and one smooth-pasting condition,

$$
\left[V^{h}(\tilde{A})\right]^{\prime}=\left[V^{o}(\tilde{A})\right]^{\prime}
$$

Note that the value of the project, $V^{o}(\tilde{A})$, is given by the profit flows after relocation of production, see Equation (25).

Making use of the value-matching and smooth-pasting conditions, the expression for the critical value $(\tilde{A})$ is obtained and likewise for the constant $B_{1}$ as

$$
\begin{gathered}
\tilde{A}=\left[\frac{\beta_{1}}{\beta_{1}-1} \times \frac{\mu-\alpha \theta+\frac{\theta \phi}{2} \sigma^{2}}{1-\frac{\delta}{2}} \times \frac{\theta \delta^{-\phi}}{(1-r)\left[\left(\frac{w}{b^{2}}+\frac{w^{*}}{b^{* 2}}\right)^{-\phi}-\left(\frac{2 w}{b^{2}}\right)^{-\phi}\right]} \times I\right]^{\frac{1}{\theta}} \\
B_{1}=\frac{\left\{\frac{1-\frac{\delta}{2}}{\mu-\alpha \theta+\frac{\theta \phi}{2} \sigma^{2}} \times \delta^{\phi} \times(1-r)\left[\left(\frac{w}{b^{2}}+\frac{w^{*}}{b^{* 2}}\right)^{-\phi}-\left(\frac{2 w}{b^{2}}\right)^{-\phi}\right]\right\}^{\frac{\beta_{1}}{\theta}}}{\beta_{1}^{\frac{\beta_{1}}{\theta}}\left[\left(\beta_{1}-1\right) \theta\right]^{1-\frac{\beta_{1}}{\theta}} I^{\frac{\beta_{1}}{\theta}-1}}
\end{gathered}
$$

Equation (32) is the trigger value of demand separating the region in $A$ space where MNE's option of offshoring remains unexercised (i.e. for $A>\tilde{A}$ ) from the one where immediate exercise of that option is perceived as optimal (i.e. for $A \leq \tilde{A}$ ).

\section{B Simulations}

The simulations relate to the critical ratio obtained in Equations (14) and (22). These simulations are conducted with reference to a benchmark case. The values of the parameters considered in the benchmark case, as well as the ranges used in the simulations of the critical ratio, were drawn from a data set of MNEs located in Portugal and investing in Poland, during the period 1995-2004. "Domestic demand excluding stocks, at 1995 prices", from the European Commission, Economic and Financial Affairs, (AMECO Database) was used as a proxy for the demand of both countries. Thus, the parameters from the equations of the critical ratio are defined as:

$\sigma$ : Volatility of demand, is the standard deviation of the natural logarithm of demand of the three years prior to entry.

$\alpha$ : Trend of the demand is the moving average of the natural logarithm of demand's rate of growth of the three years prior to entry.

$\mu$ : Discount rate is the United States "real long-term (5 years) interest rate, deflator GDP", from AMECO Database.

$w$ : The home country wage rate is the Portuguese "nominal compensation per employee: total economy", from AMECO Database.

$b$ : The home country productivity is the Portuguese "real compensation per employee, deflator GDP (total economy): performance relative to the rest of 35 industrial countries", from AMECO Database. 
$w^{*}$ : The foreign country wage rate is the Polish "nominal compensation per employee: total economy", from AMECO Database.

$b^{*}$ : The foreign country productivity is the Polish "real compensation per employee, deflator GDP (total economy): performance relative to the rest of 35 industrial countries", from AMECO Database.

I: The investment sunk cost is the United States "total assets" in Poland, from the Bureau of Economics Analysis (BEA).

$\delta$ : Since the data on the parameter for the elasticity of demand is not available, the benchmark value and the range of variation were picked arbitrarily.

$r$ : Tax rate is the Portuguese "current tax on income and wealth: corporations", from AMECO Database.

$i$ : Since the data on the tax rate deduction is not available, the benchmark value and the range of variation were picked arbitrarily.

$s$ : The Portuguese "other subsidies on production: corporations", from AMECO Database was used as a proxy for direct subsidies.

Table B-1 presents the range as well as the mean of each parameter according to the data set specified above. The mean values are used to define the benchmark case while the maximum and the minimum values bound the range used for the simulations of the critical ratio.

Table 1: Parameter Values

\begin{tabular}{lccc}
\hline \hline & Mean & Maximum & Minimum \\
$\alpha$ & 0.015 & 0.04 & -0.02 \\
$\sigma$ & 0.05 & 0.09 & 0.01 \\
$\mu$ & 0.03 & 0.35 & 0.025 \\
$w$ & 14.7 & 19.47 & 9.26 \\
$b$ & 109.17 & 95 & 121 \\
$w^{*}$ & 6.13 & 1.63 & 9.82 \\
$b^{*}$ & 122.78 & 81.5 & 153.2 \\
$I$ & 4575.57 & 3281 & 5942 \\
$\delta$ & 0.01 & 0.5 & 0.99 \\
$r$ & 0.16 & 0.2 & 0.12 \\
$s$ & 0.03 & 0.04 & 0.02 \\
$i$ & 0.01 & 0.015 & 0.02 \\
\hline \hline
\end{tabular}




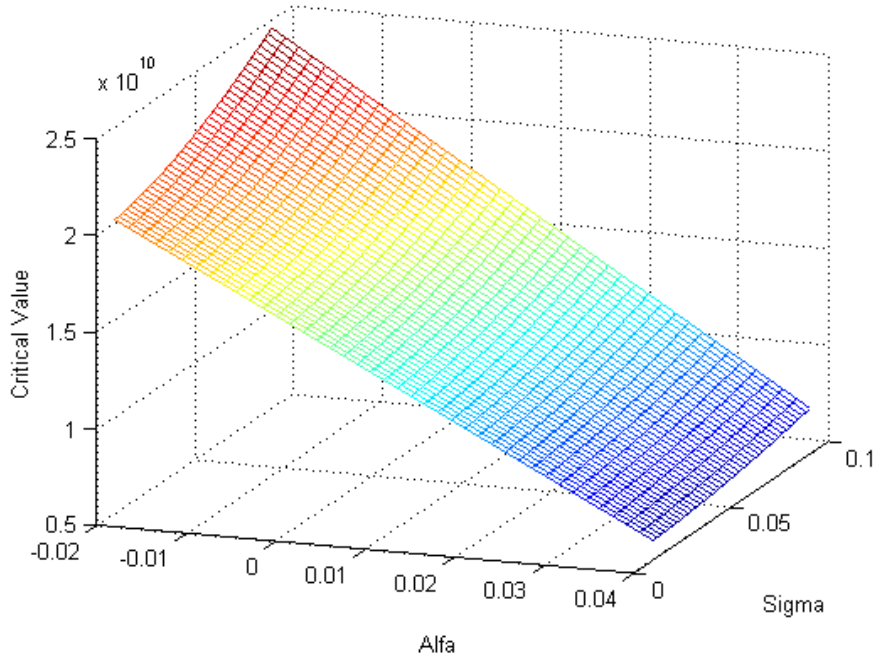

Figure 1: $\delta=0.5, \mu=0.03, w=14.7, b=109.17, w^{*}=6.13, b^{*}=122.78, I=4575.57$

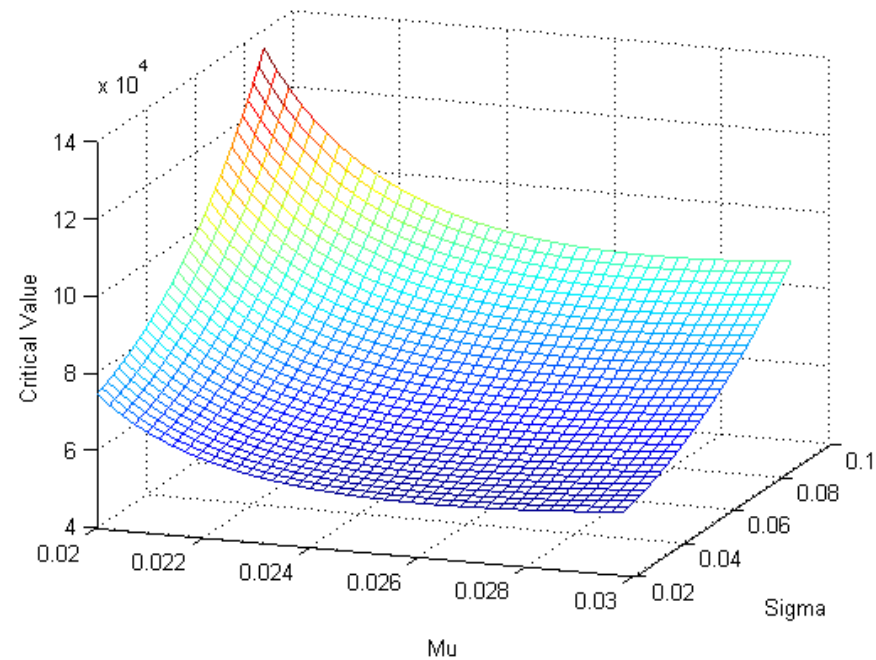

Figure 2: $\delta=0.5, \alpha=0.015, w=14.7, b=109.17, w^{*}=6.13, b^{*}=122.78, I=4575.57$ 


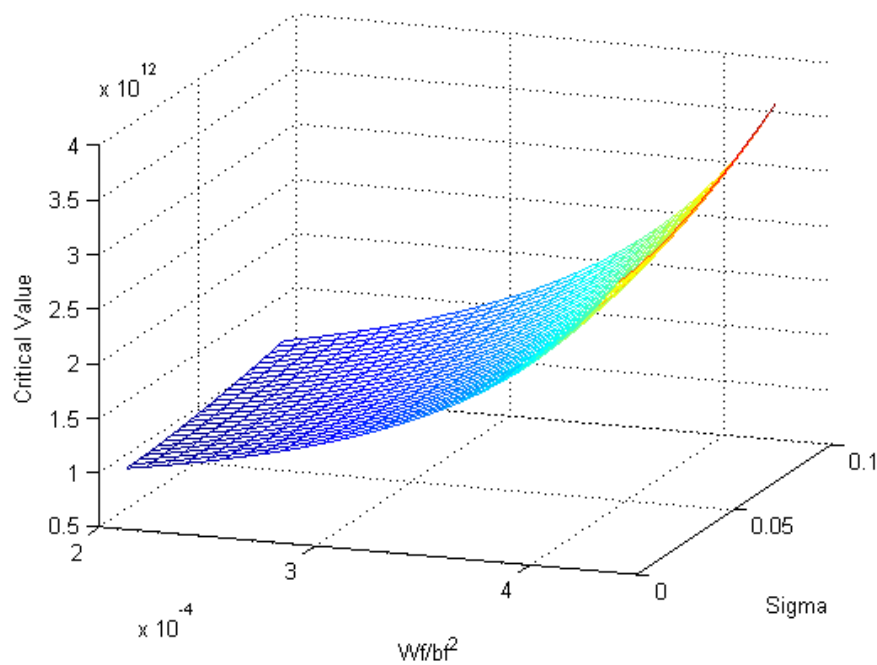

Figure 3: $\alpha=0.015, \delta=0.5, \mu=0.03, w=14.7, b=109.17, I=4575.57$

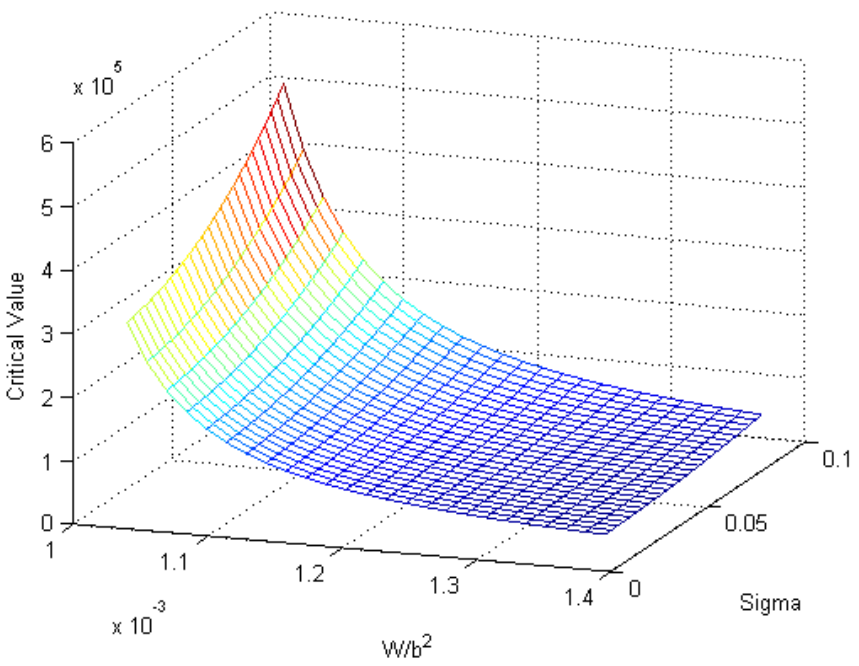

Figure 4: $\alpha=0.015, \delta=0.5, \mu=0.03, w^{*}=6.13, b^{*}=122.78, I=4575.57$ 


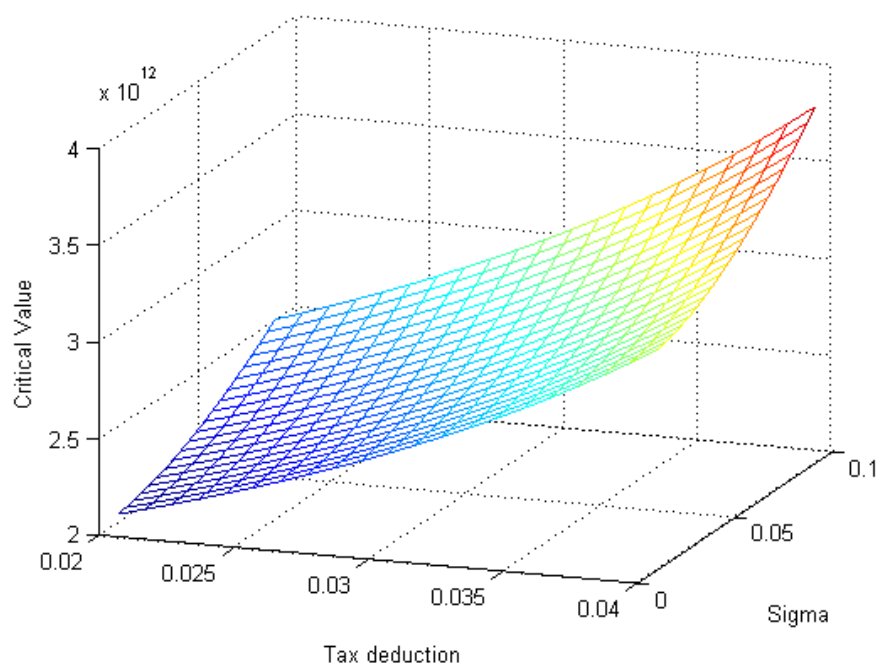

Figure 5: $\alpha=0.015, \delta=0.5, \mu=0.03, w=14.7, b=109.17, w^{*}=6.13, b^{*}=122.78$, $I=4575.57$

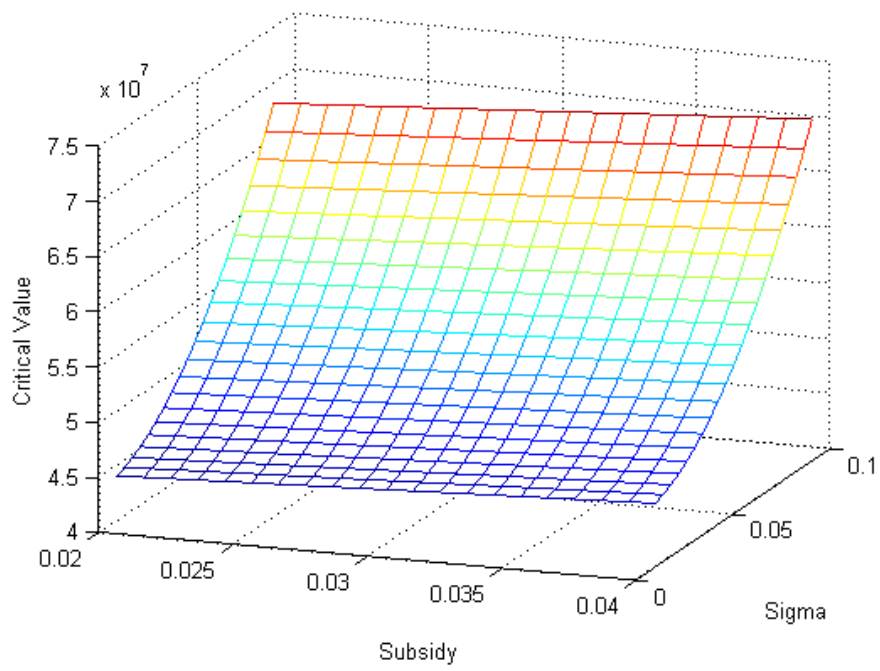

Figure 6: $\alpha=0.015, \delta=0.5, \mu=0.03, w=14.7, b=109.17, w^{*}=6.13, b^{*}=122.78$, $I=4575.57$ 